\title{
Identification of Phytochrome-Interacting Factor Family Members and Functional Analysis of MdPIF4 in Malus domestica
}

\author{
Peng-Fei Zheng, Xun Wang, Yu-Ying Yang, Chun-Xiang You, Zhen-Lu Zhang * and Yu-Jin Hao * \\ State Key Laboratory of Crop Biology, College of Horticulture Science and Engineering, Shandong Agricultural \\ University, Tai'an 271000, China; zhengpengfei96@163.com (P.-F.Z.); wx20145015@126.com (X.W.); \\ 17863807915@163.com (Y.-Y.Y.); youchunxiang@sdau.edu.cn (C.-X.Y.) \\ * Correspondence: zhangzhenluwenchao@163.com (Z.-L.Z.); haoyujin@sdau.edu.cn (Y.-J.H.)
}

Received: 30 July 2020; Accepted: 30 September 2020; Published: 5 October 2020

\begin{abstract}
Phytochrome-interacting factors (PIFs), members of the basic helix-loop-helix transcription factor family that have been extensively investigated in Arabidopsis thaliana, play essential roles in plant growth and development. However, PIF members have not been systematically investigated in apples, a worldwide perennial woody crop of economic importance. Here, seven PIF genes were identified from the Malus $\times$ domestica reference genome. Chromosomal locations, gene structures, and phylogenetic relationships of these members were analyzed. Analysis of cis-acting elements in promoter regions of MdPIF genes indicated that various elements were related to light, abiotic stress, and plant hormone responsiveness. Subsequently, subcellular localization and transcriptional activity analysis revealed that MdPIFs were typical nuclear transcription factors with transcriptional activation ability. Expression analysis demonstrated that MdPIF genes had different gene expression patterns for various abiotic factors. Moreover, overexpressed MdPIF4 reduced the sensitivity of apple calluses to abscisic acid (ABA). Our work lays foundations for further investigation of PIF functions in plant growth and development in apples.
\end{abstract}

Keywords: phytochrome-interacting factor; gene expression analysis; protein localization; ABA sensitivity; transcription activation activity

\section{Introduction}

Light is one of the most important environmental factors affecting plant growth and development [1]. Due to differences in light spectrum, intensity, direction, and photoperiod, a series of photoreceptors, including phytochrome, cryptochrome, and phototropin, have evolved to adapt plants to different light conditions [1-3]. Phytochrome is an important class of photoreceptors that perceives and responds to red and far red light, and it participates in the entire growth and development process, from seed germination to vegetative growth and maturity of plants $[4,5]$. To date, five phytochromes (phyA-phyE) have been identified in Arabidopsis, and they have two photo-interconvertible forms [6,7]. When exposed to red light, the conformation of phytochromes changes allosterically from the inactive red light- absorbing (Pr) form to the active far red light-absorbing (Pfr) form. The inactive Pr form is located in the cytosol, whereas the active Pfr form resides in the nucleus [6,7]. Upon translocation into the nucleus, phytochromes in active form interact with multiple factors to regulate the transcription of downstream target genes and mediate subsequent orchestrated photoreactions [8-11].

Phytochrome interacting factors (PIFs) are one of the most important phytochrome interacting partners, and they primarily act as negative regulators of photomorphogenesis in response to light, and maintain skotomorphogenesis in darkness [8,12]. Currently, eight PIFs (AtPIF1-AtPIF8) have been 
identified in Arabidopsis [9], and AtPIF3 was originally identified as a phytochrome-interacting protein using AtphyB as bait [13]. As basic helix-loop-helix (bHLH) transcription factor family members, all AtPIFs contain the bHLH domain, which plays a key role in the formation of homo- and heterodimers of AtPIFs [9]. In addition, the active phyB-binding (APB) motif is present in all AtPIFs, whereas the active phyA-binding (APA) motif only exists in AtPIF1 and AtPIF3 $[8,14,15]$.

In addition to being a negative regulator of photomorphogenesis in response to light $[8,16,17]$, PIFs have also been demonstrated to regulate many other pathways, including anthocyanin biosynthesis, thermomorphogenesis, hormone signaling, and responding to biotic and abiotic stresses by interacting with multiple cellular molecules [18-21]. For example, maize (Zea mays) ZmPIF1 and ZmPIF3 could improve the drought tolerance of rice by inducing stomatal closure [22,23]. AtPIF1 interacted with AtABI5 (abscisic acid insensitive 5), a basic leucine zipper (bZIP) transcription factor that is involved in the abscisic acid (ABA) signaling pathway, to regulate endogenous $A B A$ and ABA signaling pathways [24,25]. Furthermore, hypocotyl growth of the pif4 mutant is insensitive to high temperature $\left(29^{\circ} \mathrm{C}\right)$, suggesting the key role of AtPIF4 in plant thermoresponsive growth [26]. Moreover, AtPIF4 was also reported to accelerate flowering by directly activating AtFT (flowing locus T) expression in a temperature-dependent manner [27]. Therefore, PIFs are considered to be a hub in the integration of environmental and hormonal signaling pathways [28].

Apple (Malus domestica) is an important commercial fruit crop, and its production is highly affected by environmental factors, especially light $[29,30]$. PIFs play a central role in adapting plants to different light conditions; however, identification and functional analysis of PIFs in apples have not been systematically investigated, except MdPIF1 [31]. Here, we identified seven MdPIF genes using bioinformatics methods and analyzed their gene structures, chromosomal locations, conserved motifs and the cis-acting elements of their promoter regions. The expression patterns under different stresses were analyzed to better understand the function of apple PIF genes. Moreover, overexpressed MdPIF4 reduced the sensitivity of apple calluses to ABA. Our findings establish a foundation for the further functional investigation of plant PIFs.

\section{Results}

\subsection{Identification, Chromosome Localization, and Gene Structural Analysis of the MdPIF Genes}

PIFs are members of a subset of the bHLH transcription factor superfamily. It has been reported that apples have $188 \mathrm{MdbHLH}$ genes [32]. To identify the PIF members in apples, we utilized the Arabidopsis PIF protein sequences to perform a BLASTp analysis, and eight candidate MdPIFs (named MdPIF1 to MdPIF8) were obtained from apples. Depending on the presence of conserved bHLH and APB domains, seven MdPIF proteins were finally determined, and MdPIF6 (GenBank accession number: MDP0000215587) was excluded due to the absence of the APB domain (Table 1 and Figure S1). Sequence analysis revealed that these MdPIF proteins varied widely in length, from 449 amino acid (aa) to 1040 aa, and their molecular mass ranged from $48 \mathrm{KDa}$ to $113 \mathrm{KDa}$. Other characteristics, including gene IDs, genomic positions, grand average of hydropathicity, and pI values, of the MdPIF proteins are summarized in Table 1.

Based on the genomic location information obtained from the Genome Database for Rosaceae (GDR), the MdPIF genes were mapped onto seven apple chromosomes (Chr): Chr 4, Chr 7, Chr 9, Chr 10, Chr 12, Chr 14, and Chr 17, respectively (Figure 1a). By analyzing the genome DNA sequences, we found that the introns of these MdPIFs ranged from 5 to 18 in number. MdPIF5 contained the highest number of introns (18), whereas MdPIF8 had only five introns. One group of MdPIF genes (MdPIF4 and 7) contained the same number of introns/exons (Figure 1b). In addition, MdPIF2 and MdPIF3, both of which were located at the same branch in the phylogenetic tree constructed based on the MdPIF coding sequences (Figure S2), had similar intron/exon distributions. 
Table 1. Information about the PIF members found in apples.

\begin{tabular}{|c|c|c|c|c|c|c|c|c|c|c|}
\hline Gene Name & Gene ID & $\begin{array}{l}\text { Chromosome } \\
\text { Location }\end{array}$ & Position & $\begin{array}{l}\text { mRNA Length } \\
\text { (bp) }\end{array}$ & $\begin{array}{l}\text { CDS Length } \\
\text { (bp) }\end{array}$ & $\begin{array}{l}\text { Amino Acid } \\
\text { Length (aa) }\end{array}$ & $\begin{array}{l}\text { Molecular Weight } \\
\text { (Da) }\end{array}$ & TheoreticalpI & $\begin{array}{l}\text { Grand Average of } \\
\text { Hydropathicity } \\
\text { (GRAVY) }\end{array}$ & Best Hits \\
\hline MdPIF1 & MDP0000289642 & chr10 & 16985872-16992614 & 6743 & 1920 & 639 & 70621.62 & 8.55 & -0.59 & AtPIF1 \\
\hline MdPIF2 & MDP0000205358 & chr4 & 18339668-18342979 & 3312 & 2235 & 744 & 80495.75 & 6.52 & -0.645 & AtPIF2 \\
\hline MdPIF3 & MDP0000290263 & chr12 & 27035201-27038407 & 3207 & 2127 & 708 & 75773.44 & 5.83 & -0.626 & AtPIF3 \\
\hline MdPIF4 & MDP0000198404 & chr17 & 11357450-11361687 & 4238 & 1842 & 613 & 67336.57 & 7.06 & -0.676 & AtPIF4 \\
\hline MdPIF5 & MDP0000254650 & chr9 & $11107477-11118877$ & 11401 & 3123 & 1040 & 113679.29 & 8.76 & -0.52 & AtPIF5 \\
\hline MdPIF7 & MDP0000319248 & chr14 & 26344135-26351096 & 6962 & 1746 & 581 & 64713.13 & 9.96 & -0.903 & AtPIF7 \\
\hline MdPIF8 & MDP0000439540 & $\mathrm{chr} 7$ & 10087113-10092308 & 5196 & 1350 & 449 & 48033.51 & 7.72 & -0.445 & AtPIF8 \\
\hline
\end{tabular}

$\mathbf{a}$

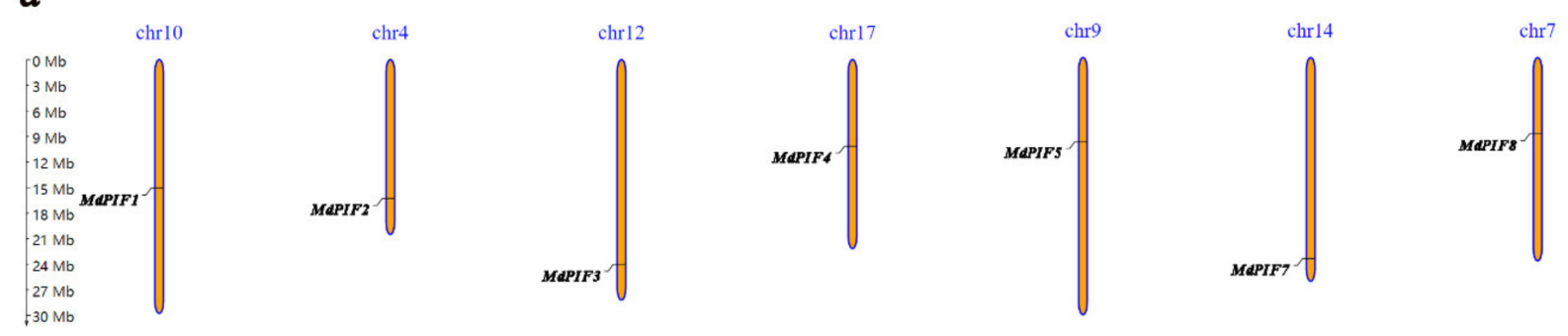

b

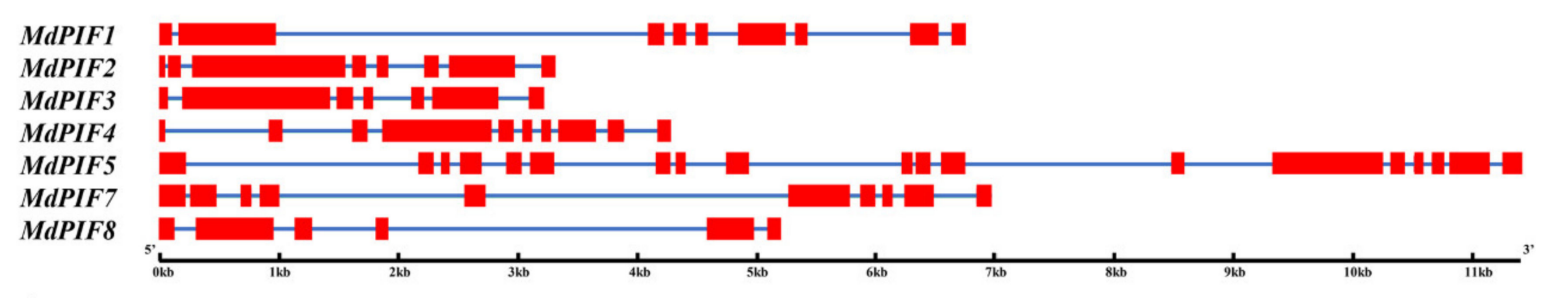

Legend:

Figure 1. Chromosomal location and gene structure (intron/exon) of the MdPIF genes. (a) Chromosomal location of seven MdPIF genes on seven apple chromosomes.

(b) Gene structures of the MdPIF genes. Red boxes indicate exons and blue lines indicate introns. 


\subsection{Phylogenetic Analysis, Multiple Sequence Alignment, and Prediction of Conserved MdPIF Motifs}

As PIFs are bHLH transcription factors that are conserved among different plant species, we next conducted a phylogenetic analysis based on the protein sequences of PIFs from apple, Arabidopsis, and rice (Oryza sativa) to investigate their evolutionary relationship. We found that MdPIF proteins were categorized into four groups. MdPIF1 belonged to group I; MdPIF4 and MdPIF5 were in group II; MdPIF2 and MdPIF3 were assigned into group III; and MdPIF7 and MdPIF8 were categorized into group IV (Figure 2a). Moreover, the MdPIFs had a closer relationship with AtPIFs than with OsPIFs, which was probably because both apple and Arabidopsis species are dicotyledons, whereas rice species are monocotyledons.

The presence of bHLH and APB domains has been developed as a basic criterion for screening PIF members. Here, the two highly conserved domains were identified in all MdPIF proteins (Figure 2b and S3a). In addition, an APA domain was also found to be present at the $\mathrm{N}$ terminal of several MdPIF proteins (MdPIF1, MdPIF2, MdPIF3, MdPIF4, and MdPIF5) (Figure 2b and S3b), which is similar to AtPIF1 and AtPIF3 [8,15].

Using the MEME motif analysis program, we predicted 15 motifs in the MdPIF proteins (Figure 3). Among them, motif 1 (HLH motif) and motif 3 (APB motif) are widely distributed in all MdPIF proteins. Interestingly, we found that MdPIF members within the same evolutionary branch share a similar motif distribution. For example, MdPIF2 and MdPIF3, both of which are located on the same branch, have highly similar motif composition, and this was also observed for MdPIF4 and MdPIF5 (Figure 3).

$\mathbf{a}$

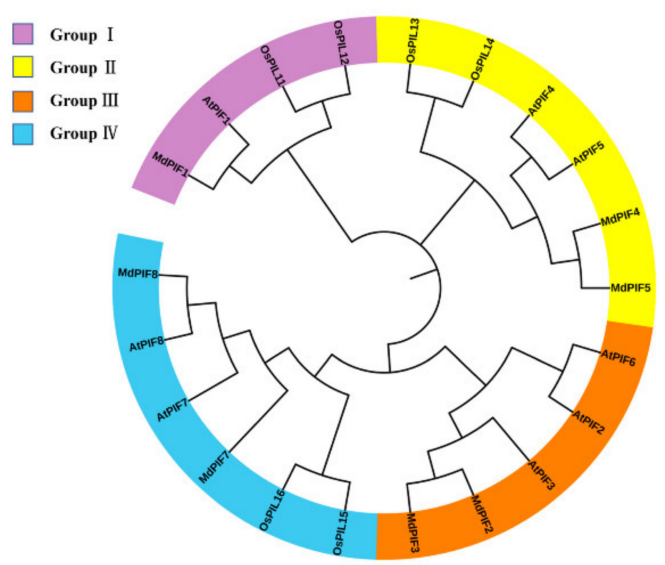

b

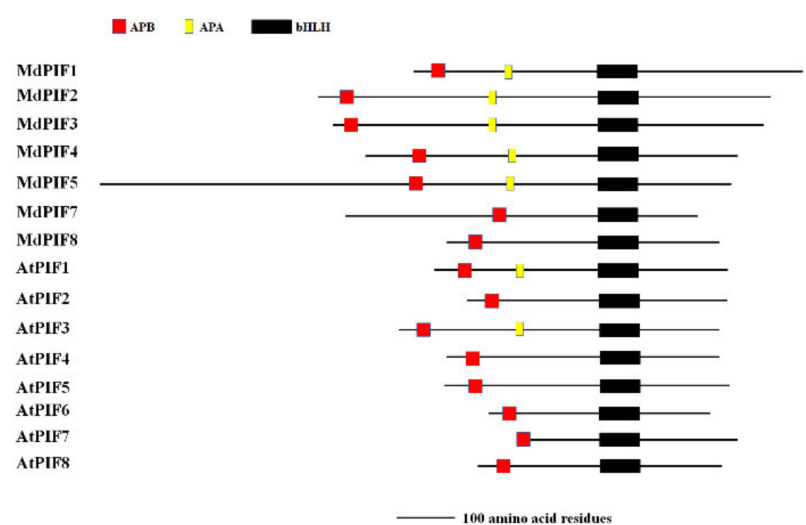

Figure 2. Analysis of phylogenetic relationship and conserved domains of MdPIFs. (a) Unrooted phylogenetic tree of PIF proteins from Malus domestica, Arabidopsis thaliana, and Oryza sativa. MEGA5.1 was used to construct the phylogenetic tree based on the PIF protein sequences, and the four distinct subgroups of PIF proteins are shown. Interactive Tree of Life (iTOL) online software was used to annotate and review the phylogenic tree. AtPIF1: AT2G20180; AtPIF2: AT2G46970; AtPIF3: AT1G09530; AtPIF4: AT2G43010; AtPIF5: AT3G59060; AtPIF6: AT3G62090; AtPIF7: AT5G61270; AtPIF8: AT4G00050; OsPIL11: Os12g0610200; OsPIL12: Os03g0639300; OsPIL13: Os03g0782500; OsPIL14: Os07g0143200; OsPIL15: Os01g0286100; OsPIL16: Os05g0139100. (b) Motif comparisons of the MdPIF and AtPIF proteins. The presence of APA, APB, and bHLH motif is depicted as boxes. Bar $=100$ amino acid residues. 

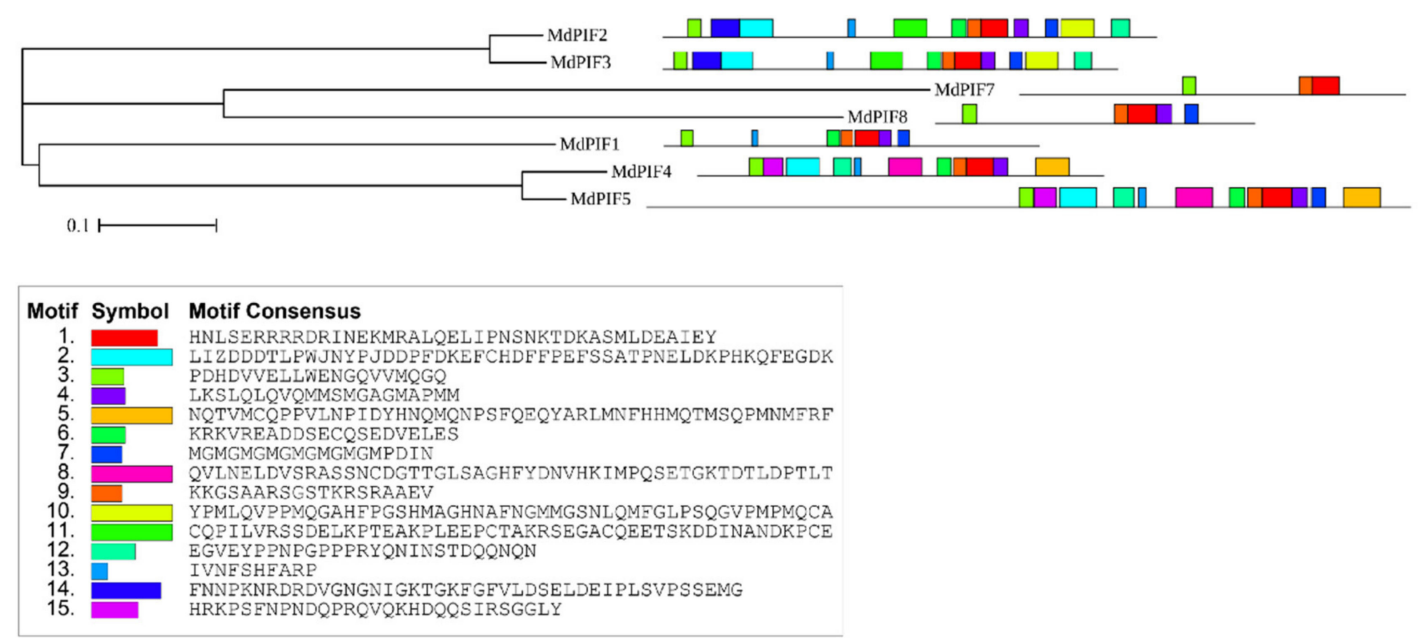

Figure 3. Schematic representation of the conserved motifs predicted in the MdPIF proteins. The MEME program was used to predict the conserved motifs, and TBtools was used to show the results.

\subsection{Analysis of Cis-Acting Elements in the MdPIF Gene Promoters}

PIFs are reported to be involved in plant responses to multiple abiotic factors, and cis-acting elements in the promoter region play a critical role in these processes $[8,33,34]$. Thus, we next analyzed the cis-acting elements in the promoter regions of MdPIF genes to explore their potential regulatory patterns (Figure S4). The results revealed that more than 26 elements are distributed with the promoters of the MdPIF genes (Table S2). Based on their function, the cis-acting elements were divided into three groups: light-, hormone-, and stress-responsiveness (Table 2). Among these, light-responsive elements were present in all MdPIF gene promoter sequences, including G-box (TACGAT) [35], ACE (CTAACGTATT), LAMP (CTTTATCA), and so on (Table S2). Plant hormonal-responding elements, such as ABRE (ACGTG), GARE (TCTGTTG), and CGTCA, that were involved in responding to ABA, gibberellin (GA), and jasmonic acid (JA), respectively, were also identified in the promoters of MdPIF genes (Table S2). In addition, multiple elements responding to abiotic stresses were also found (Table 2 and Table S2). For instance, MdPIF7's promoter contained cis-acting elements responding to low temperature (LTR: CCGAAA) and wounds (WUN-motif: AAATTTCCT). Collectively, the presence of these cis-acting elements indicated that MdPIFs might be involved in multiple responses, including responses to light, hormones, and abiotic stresses, which need further efforts to elucidate.

Table 2. Cis-acting element analysis in the MdPIF gene promoters.

\begin{tabular}{|c|c|c|c|c|c|c|c|c|c|c|c|}
\hline Gene & $\begin{array}{c}\text { Light } \\
\text { Response }\end{array}$ & & & $\begin{array}{l}\text { Hormone } \\
\text { Response }\end{array}$ & & & & & $\begin{array}{l}\text { Stress } \\
\text { Response }\end{array}$ & & \\
\hline & & AUX & $\mathrm{ABA}$ & GA & JA & SA & DT & LT & DnS & WD & AAI \\
\hline MdPIF1 & $4 / 1$ & & & & $1 / 1$ & $1 / 0$ & & $0 / 1$ & & & \\
\hline MdPIF2 & $8 / 5$ & & $1 / 2$ & & $1 / 1$ & & $0 / 1$ & & $1 / 0$ & & $1 / 0$ \\
\hline MdPIF3 & $7 / 4$ & & $0 / 2$ & $1 / 0$ & & & $1 / 1$ & & $0 / 1$ & $0 / 1$ & $2 / 1$ \\
\hline MdPIF4 & $8 / 5$ & $1 / 0$ & $3 / 2$ & $1 / 0$ & $1 / 1$ & & & & & & $0 / 1$ \\
\hline MdPIF5 & $6 / 6$ & & $1 / 1$ & & $2 / 0$ & & $1 / 0$ & & $1 / 0$ & & $1 / 3$ \\
\hline MdPIF7 & $6 / 3$ & & $1 / 1$ & $1 / 2$ & & & & $0 / 1$ & & $1 / 1$ & $2 / 1$ \\
\hline MdPIF8 & $7 / 2$ & & $0 / 1$ & & & & & & $1 / 0$ & & $1 / 1$ \\
\hline
\end{tabular}

AUX, auxin; ABA, abscisic acid; GA, gibberellin; JA, MeJA; SA, salicylic acid; DT, drought; LT, low temperature; Dns, defense and stress; WD, wound; AAI, anaerobic induction. The numbers in the table represent the number of cis-acting elements on the positive and negative chains. 


\subsection{Expression Profiles of the MdPIF Genes}

PIFs are important light-responsive genes, therefore we next analyzed the expression profiles of all MdPIF genes in response to diurnal rhythm. We first utilized qRT-PCR to determine the expression levels of MdPIF genes in different organs, including the root, stem, leaf, flower, and fruit. All the MdPIF genes had relatively similar expression patterns. They all had highest expression level in the leaf and the lowest expression level in the flower and fruit (Figure 4a-g), except MdPIF7 had the lowest expression level in the stem (Figure $4 \mathrm{f}$ ).

MdPIF1, 3, 4, 5, and 7 had similar expression patterns in responding to diurnal rhythm. The transcript levels of the five genes increased significantly overnight and fell dramatically during the day. Among them, MdPIF5 had a peak change at 8:00 p.m. and its highest level was similar to that observed at dawn. However, the expression level of MdPIF2 and MdPIF8 peaked during the day. MdPIF2 reached the highest level at 12:00 a.m. and then decreased rapidly and gradually accumulated at night. The expression of MdPIF8 decreased from 4:00 p.m. to 8:00 p.m., and re-accumulated overnight (Figure 4h). Generally, the expression pattern of MdPIF genes in response to diurnal cycles was similar to that of PIF4 and PIF5 from both Arabidopsis and maize, of which the transcript levels increased during the night, peaked at dawn, and dropped during the day $[36,37]$.

a

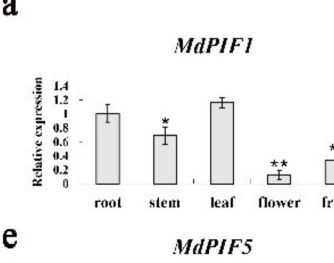

e
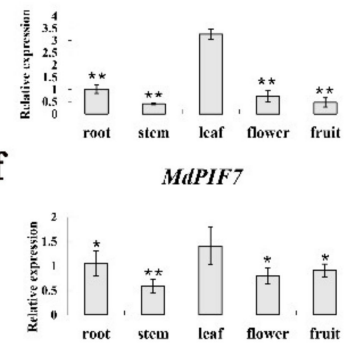

$\mathrm{g}$

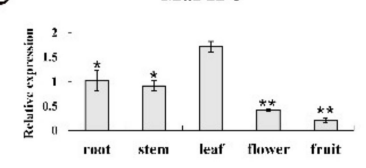

$\mathrm{b}$

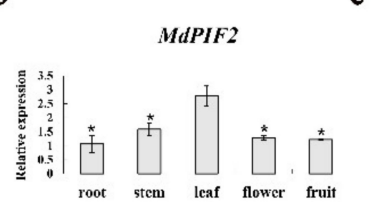

$\mathrm{c}$

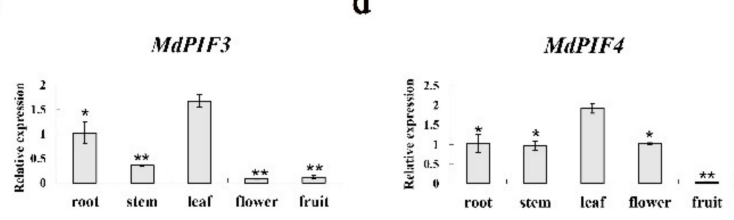

$\mathrm{h}$

\section{circadiam rhythms}

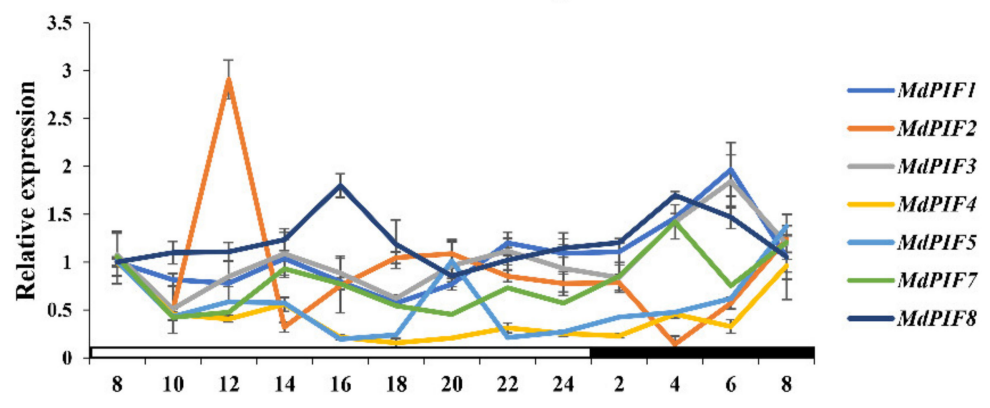

Figure 4. Expression profiles of the MdPIF genes. Expression profile of MdPIF1 (a), MdPIF2 (b), MdPIF3 (c), MdPIF4 (d), MdPIF5 (e), MdPIF7 (f), and MdPIF8 (g) in various apple tissues. 18S ribosomal RNA was used as an internal control for qRT-PCR analysis. Data are mean \pm SD of three independent biological replicates. Asterisks denote significant differences compared with leaf tissue ${ }^{*}, p<0.05$; $* *, p<0.01$ ). (h) Expression profile of the MdPIFs in response to day and night. The light conditions are from 8 o'clock to24 o'clock, followed by $8 \mathrm{~h}$ of dark environment. Data are mean $\pm \mathrm{SD}$ of three independent biological replicates. Asterisks denote significant differences from control $\left(^{*}, p<0.05\right.$; $* *, p<0.01)$.

\subsection{Subcellular Localization and Transcriptional Activity Analysis of MdPIFs}

Nuclear localization is one of the key common features of transcription factors. Therefore, we next detected the subcellular localization of MdPIF1, MdPIF3, MdPIF4, and MdPIF8, which were selected as representative members of the four groups in the phylogenetic tree (Figure 2a). MdPIFgreen fluorescent protein (GFP) constructs were injected into Nicotiana benthamiana leaves through agroinfiltration. After two days' treatment in darkness, the samples were observed under a confocal 
microscope. All MdPIFs were examined in the nucleus (Figure 5a), which is consistent with the previous reports that PIFs in Arabidopsis and maize were all localized in the nucleus [12,38].

The transcriptional activity of MdPIF proteins was also verified in yeast. The coding sequences of MdPIF genes were inserted into the pGBKT7 vector (Figure 5b). The empty pGBKT7 vector and pGBKT7-MdMYB23 served as the negative and positive controls, respectively. All of the yeasts within different constructs grew normally on the SD/-Trp medium (Figure 5c). After being transferred to SD/-Trp/ -His/-Ade medium supplemented with $\mathrm{X}$ - $\alpha$-gal, blue yeast colonies were present when transformed within pGBKT7-MdPIFs or pGBKT7-MdMYB23, whereas the negative control showed nothing. These results indicated that MdPIF proteins were characterized with transcriptional activity in yeast cells.

a

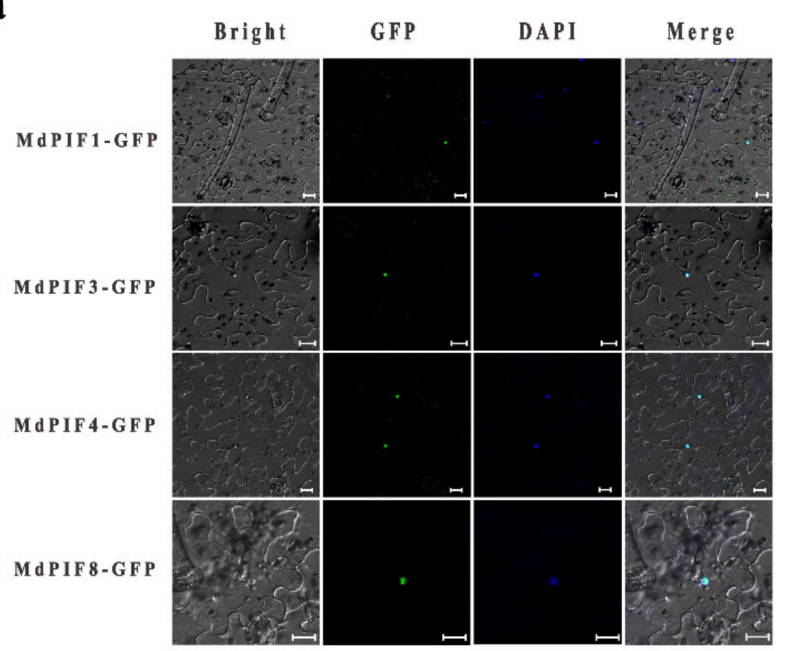

b

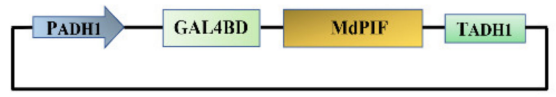

c

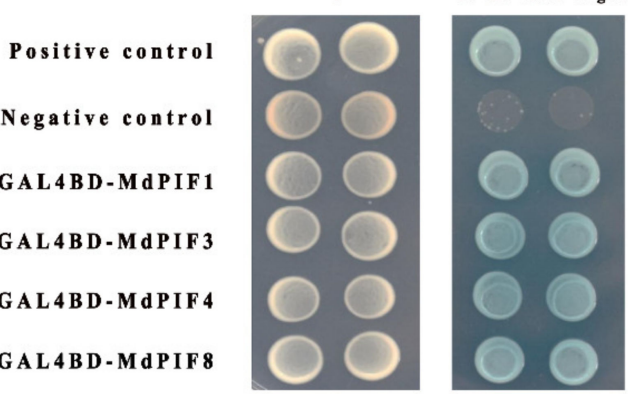

Figure 5. Subcellular localization and transactivation assay of MdPIF proteins. (a) Subcellular localization of MdPIF proteins. Scale bar $=20 \mu \mathrm{m}$. (b) Schematic diagram of the MdPIF-pGBKT7 structure. (c) The construct of pGBKT7-MdPIF was transformed into yeast strain AH109 and examined on SD/-Trp and $\mathrm{SD} /$-Trp/-His/-Ade/X- $\alpha$-gal plates.

\subsection{Expression Analysis of MdPIFs in Response to Abiotic Stresses and Hormones}

Based on the analysis of cis-acting elements in the promoters of MdPIF genes (Tables 2 and S2), it was reasonable to hypothesize that $M d P I F s$ were involved in responding to abiotic factors and plant hormones. To verify our hypothesis, we next investigated the expression patterns of the four representative MdPIF genes (MdPIF1, MdPIF3, MdPIF4, and MdPIF8) after being treated by $100 \mathrm{mM} \mathrm{NaCl}$ (which mimicked salt stress), 8\% PEG 6000 (which mimicked drought stress), $100 \mu \mathrm{M}$ indole-3-acetic acid (IAA), $100 \mu \mathrm{M}$ ABA, and $100 \mu \mathrm{M} \mathrm{GA}$, respectively.

As shown in Figure 6, the expression level of MdPIF genes in the treatment groups indicated the responsiveness of MdPIFs to several abiotic stresses and hormones, despite the fluctuating expression of MdPIFs in the control group. Specifically, under $\mathrm{NaCl}$ treatment, the expression levels of all MdPIF genes were significantly decreased at the 6-h point compared to that of the control, suggesting that salt stress repressed transcription of MdPIF genes and that the inhibited expression of MdPIFs may be involved in resistance to salt stress (Figure 6a). Furthermore, when treated with PEG 6000, expression levels of MdPIF1 and MdPIF3 increased significantly after $12 \mathrm{~h}$, whereas those of MdPIF4 and MdPIF8 were upregulated dramatically at an early stage (the 1-h and 2-h points, respectively). However, when expression levels of MdPIF8 decreased after the peak ( $2 \mathrm{~h})$, MdPIF4 expression levels remained at high levels and peaked at $6 \mathrm{~h}$ (Figure 6b).

In addition to responding to abiotic stresses, the expression levels of MdPIF genes were also influenced by exogenous hormones to vary degrees. For instance, under IAA treatment, expression levels of all MdPIF genes were downregulated after $3 \mathrm{~h}$, and then gradually increased from $6 \mathrm{~h}$ to $12 \mathrm{~h}$ (Figure 6c). When treated with ABA, MdPIF3 and MdPIF4 were all expressed highly after $12 \mathrm{~h}$ 
compared to controls, whereas MAPIF1 and MAPIF8 expression levels were upregulated at both $1 \mathrm{~h}$ and $12 \mathrm{~h}$ (Figure 6d). Furthermore, MdPIF1, MdPIF3, and MdPIF4 showed significantly increased transcript levels $3 \mathrm{~h}$ post-treatment with GA, whereas MdPIF8 was expressed highly after $12 \mathrm{~h}$ (Figure 6e). Collectively, these data suggest that the apple MdPIF genes were widely involved in multiple abiotic stress and hormones responses.

a

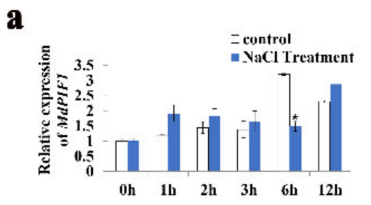

b

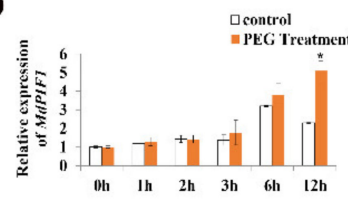

c

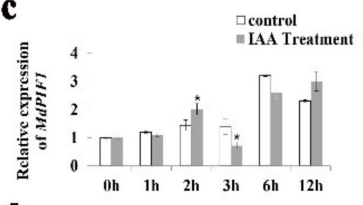

d
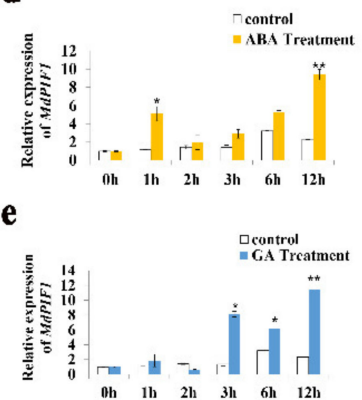
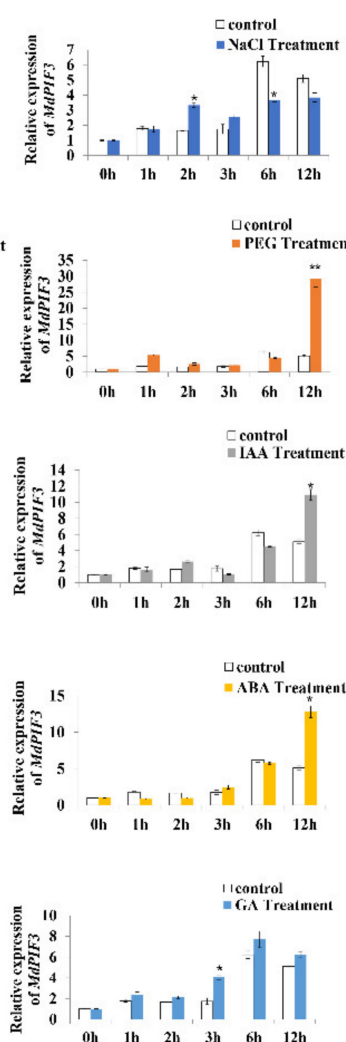
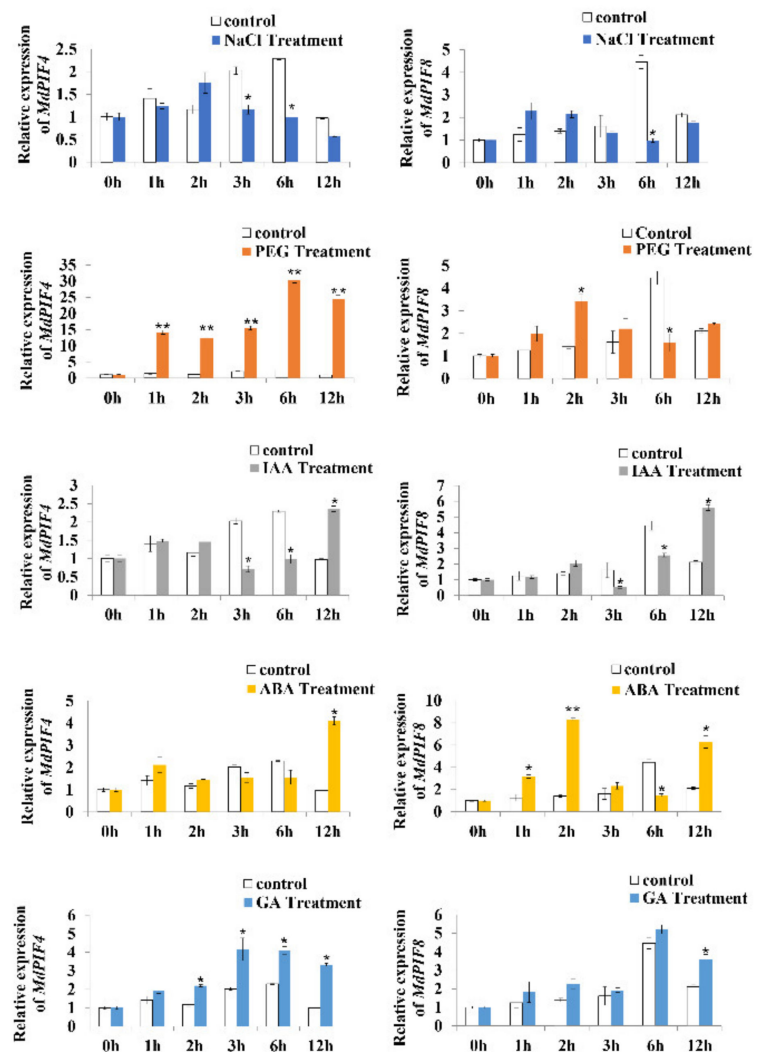

Figure 6. Expression analysis of MdPIF genes in response to abiotic stressors and hormones. Expression levels of the MdPIFs in response to $\mathrm{NaCl}$ (a), PEG 6000 (b), indole-3-acetic acid (IAA) (c), ABA (d), and $\mathrm{GA}(\mathbf{e})$. Data are mean $\pm \mathrm{SD}$ of three independent replicates. Asterisks denote significant differences from control $\left({ }^{*}, p<0.05 ; * *, p<0.01\right)$.

\subsection{MdPIF4 Overexpression Reduces Sensitivity to ABA in Apple Calluses}

Among the seven MdPIF gene promoters, a large number of ABA-responsive elements were found, indicating these apple PIF genes might be involved in the ABA response. The promoter of MdPIF4 contained the largest number of ABA-responsive elements (Table 2), and the expression level of MdPIF4 was significantly influenced by ABA treatment (Figure 6d). We therefore predicted that MdPIF4 was of highly likely to be involved in ABA signaling pathways. We first obtained two transgenic lines of apple calluses with overexpressed MdPIF4. Transgenic calluses generated much higher transcription levels of MdPIF4 compared to the WT control, suggesting that MdPIF4 was successfully transformedinto the callus (Figure 7a). In mock treatment, the growth of the WT and the MdPIF4-OE callus were consistent, and they had similar fresh weights, as well as MDA content, which is the most mutagenic product of lipid peroxidation and its content has been developed to be an important index for measuring the degree of plant damage caused by stresses [39-41] (Figure 7b,d). Exogenous ABA treatment restricts cell elongation and thus inhibits apple callus growth, which has been demonstrated by previous reports [42]. When supplied with ABA in the medium, the growth of WT and MdPIF4-OE calluses was inhibited compared to that in mock conditions, and higher ABA concentrations made it worse (Figure $7 \mathrm{~b}$ ). Nevertheless, the MdPIF4-OE callus grew much better than WT, suggesting that overexpressed MdPIF4 in apple calluses reduces their sensitivity to ABA (Figure $7 \mathrm{~b}$ ). The fresh weights of apple calluses with 
overexpressed MdPIF4 were significantly higher than that of WT under ABA treatment (Figure 7c), which was consistent with the phenotypic results displayed in Figure $7 \mathrm{~b}$. Moreover, the MdPIF4-OE callus had a lower MDA content compared to that of WT, suggesting that overexpressed MdPIF4 alleviated the damage caused by $\mathrm{ABA}$ and thus promoted the callus growth more effectively under ABA treatment.

To further investigate the role of MdPIF4 in regulating ABA response, we tested the expression pattern of several ABA response genes in WT and transgenic apple calluses. ABA response genes, such as MdEM1, MdEM6, MdRAB18, and MdRD29A, that were reported to be involved in ABA downstream signaling pathways, as well as MdAREB3.1, which regulates ABA signaling pathways [43], were significantly downregulated in the MdPIF4-OE callus compared to that in WT apples (Figure 7e), suggesting that MdPIF4 might be involved in modulating the expression of ABA response genes to regulate $\mathrm{ABA}$ sensitivity.

a

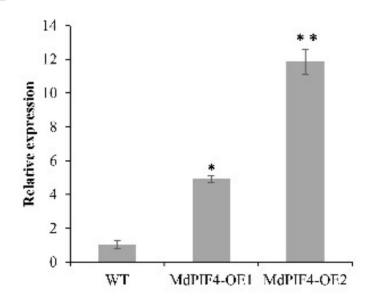

c

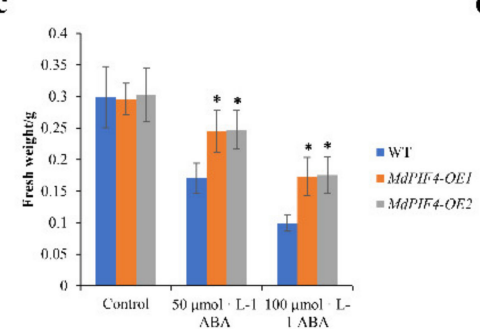

b

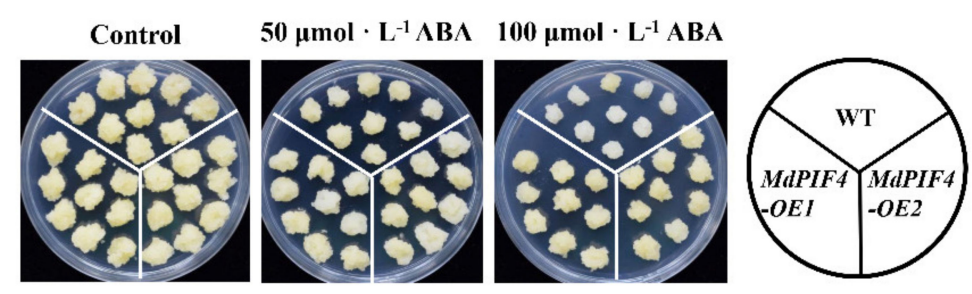

d

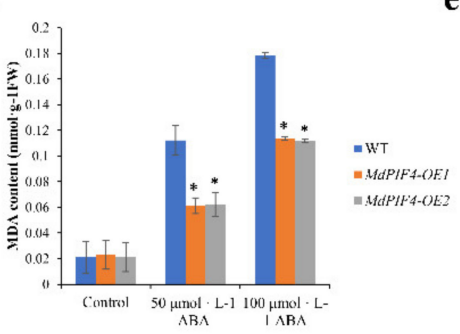

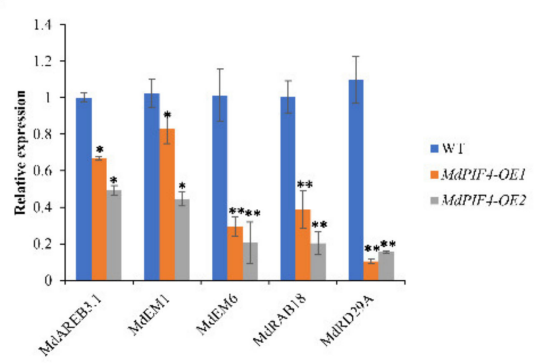

Figure 7. Reduced ABA sensitivity of MdPIF4 transgenic apple callus. (a) Expression analysis of MdPIF4 in WT and transgenic calluses. 18S ribosomal RNA was used as an internal control. (b) The phenotypes of 14-day-old transgenic and WT apple calluses cultured on Murashige and Skoog (MS) medium containing different concentrations of ABA for 20 d. (c) Statistical analysis of fresh weights for the transgenic and WT apple calluses after treatment. (d) Statistical analysis of the MDA concentrations in transgenic and WT apple calluses after treatment. (e) The gene expression of ABA response genes in WT and transgenic calluses after ABA treatment. Data are mean \pm SD of three independent replicates. Asterisks denote significant differences from control $\left({ }^{*}, p<0.05 ;{ }^{* *}, p<0.01\right)$.

\section{Discussion}

With the completion of whole genome sequencing of apples [44-46], many transcription factor families have been identified, such as MYB [47], WRKY [48], BBX [49], and bHLH [32]. Some of the pivotal genes have been characterized and their biological functions have been widely studied, such as MYB1 [50], WRKY40 [51], and BBX22 [52]. Although PIFs play an important role in plant growth and development, systematical characterization and functional investigation have not been conducted with the PIF family in apple, except with MdPIF1 [31]. Here, a systematic analysis of the MdPIF gene family was performed, which provides directions for further research on the PIF gene in apples and in the selection of important trait genes. 


\subsection{PIFs Are Transcription Factors Conserved among Different Plant Species}

In this study, seven MdPIF genes were identified in apples, which is similar to the numbers reported in other plants—eight for Arabidopsis [9], six for rice [53], and seven for maize [38]. Phylogenetic analysis showed that MdPIFs were divided into four clades (Figure 2a). The results are different from previous reports on the evolutionary relationship of PIF proteins in maize and rice, in which PIF proteins are clustered into three clades [38,53]. The analysis of MdPIF protein sequences showed that all MdPIFs share the conserved bHLH domain and APB motif. Five MdPIFs (MdPIF1, MdPIF2, MdPIF3, MdPIF4, and MdPIF5) have the APA motif, similar to AtPIF1 and AtPIF3, suggesting that these MdPIFs might be close to AtPIF1 and AtPIF3 on an evolutionary scale (Figure 2b). Moreover, it is worth mentioning that MdPIF7 and MdPIF8 display an amino acid substitution in the APB domain that alters the conserved Q residue to $X$ and E, respectively (Figure S3a) [14]. Meanwhile, additions of amino acid residue in bHLH domain were specific in MdPIF1 and MdPIF2 compared to other MdPIFs, suggesting that they may have a potentially unique function (Figure S3a). Expression pattern analysis in different apple tissues found that all MdPIF genes were constitutively expressed in the tissues examined, with relatively high levels in leaves (Figure 4a-g), which is similar to the expression pattern of AtPIFs and ZmPIFs [38,54]. The nuclear localization (Figure 5a) and transcriptional activation activity (Figure 5c) of MdPIFs indicated that they are typical transcription factors, and that they may function as positive regulators of downstream gene expression.

\subsection{PIFs Act as a Molecular Hub in Integrating Environmental and Hormonal Signaling Pathways}

In addition to being negative regulators of photomorphogensis, a growing body of evidence indicates that PIFs act as a signaling hub and play key roles in numerous processes, including anthocyanin synthesis [18]; resistance to drought [22,23], salt [23], and cold [55]; signaling pathways of plant hormones (GA, BR, and auxin) [56]; and even in regulating plant immunity [57].

The cis-acting elements in the gene promoter region can be recognized by multiple cellular proteins, such as transcription factors, to regulate transcription and gene expression in response to environmental and hormonal signals. For example, AtPIF4 mRNA expression is activated by high temperature. It was further found that high temperature inactivates AtELF3 (early flowering 3), which represses AtPIF4 expression by directly binding to its promoter [56]. Moreover, the binding affinity of AtELF3 to the AtPIF4 promoter is decreased at a high temperature $\left(27^{\circ} \mathrm{C}\right)$, compared to that at a normal temperature $\left(22^{\circ} \mathrm{C}\right)$ [58]. When analyzing the promoter of $M d P I F$ genes, light-responsive related elements appear to be significantly abundant (Table 2 and Table S2). Combining the changes in the transcription level of MdPIF genes in day and night in Figure $4 \mathrm{~h}$, we found that MdPIF genes were regulated by a light-mediated diurnal rhythm. In addition to the photoperiod, multiple cis-acting elements were predicted to respond to plant hormones (ABA, GA, and JA) and abiotic stresses (drought, low temperature, and wound) (Table 2 and Table S2). Previous studies have shown that some hormones, such as ABA, GA, and JA, play a key role in regulating plant responses to stress conditions [59]. Our data also confirmed that MdPIF expression could be induced by several abiotic stresses and hormones (Figure 6). For example, MdPIF1 and MdPIF4 were significantly upregulated by drought and GA treatments (Figure 6b,e). Motifs that were involved in the response to drought (MBS: CAACTG) and ABA (ABRE: ACGTG) were predicted to be present in MdPIF3's promoter (Table 2 and Table S2), and the expression level of MdPIF3 was significantly induced after drought and ABA treatment for $12 \mathrm{~h}$ (Figure $6 \mathrm{~b}, \mathrm{~d}$ ). In addition, cis elements that function in response to GA were present in the promoter of MdPIF3 and MdPIF4, and both of them were induced to express to varying degrees by GA treatment (Figure 6e). Moreover, ABA responsive motifs were found in the promoters of most MdPIF genes, and these genes were induced to varying degrees under ABA treatment (Figure 6d). These data suggested that the cis elements in the promoter region of MdPIFs may be functional in their response to abiotic stresses and hormones.

A growing body of evidence indicates that PIF4 acts as a key integrator of multiple signaling pathways [56], including light (skomotorphogenesis) and temperature signaling pathways [21], hormonal signaling pathways (auxin, GA, and BR), and circadian clock output pathways. Here, we 
found that ABA treatment affected the MdPIF4 expression (Figure 6d), and overexpressed MdPIF4 decreased the sensitivity of apple calluses to ABA by downregulating the expression of ABA-responsive genes (Figure 7), indicating that MdPIF4 might play a negative regulatory role in ABA signaling pathways, which has not been reported yet, and the mechanism behind this still needs further investigation. In addition, several genes involved in ABA response have been identified in apples. The expression of seven $M d A G O$ genes from the $M d A G O$ family were significantly enhanced by ABA treatment [60]. Overexpression of MdSINA2 increased ABA sensitivity in apple calluses and Arabidopsis [61]. Although the regulatory mechanism remains to be resolved, the identification of these ABA-responsive genes has enriched our knowledge of the ABA signaling pathway network in apples, and will provide a basis for future research on their functions.

\section{Materials and Methods}

\subsection{Plant Materials and Growth Conditions}

Apple tissue (Malus domestica 'Royal Gala') samples (stem, young root, mature leaf, flower, and ripening fruit) were collected from three 10-year-old apple trees in an artificially managed orchard to investigate expression pattern of the MdPIFs [62,63]. Of note, ripening fruits were collected 150 days after bloom and roots were taken from young roots that were newly grown in the year. Tissue-cultured apple (Malus domestica 'Royal Gala') seedlings were maintained on Murashige and Skoog (MS) medium with $0.5 \mathrm{mM}$ 6-benzylaminopurine (6-BA) and $0.1 \mathrm{mM}$ indole-3-acetic acid (IAA) during a $16 \mathrm{~h} / 8 \mathrm{~h}$ of light/dark photoperiod (light intensity $70 \mu \mathrm{mol} \mathrm{m}^{-2} \mathrm{~s}^{-1}$ ) in a culture room at $25^{\circ} \mathrm{C}$ [32]. After $21 \mathrm{~d}$ of growth, the seedlings were transferred to root-inducing medium (MS medium within $0.1 \mathrm{mM} \mathrm{IAA}$ ) to induce root growth [64]. These tissue-cultured apple seedlings were used to measure diurnal expression

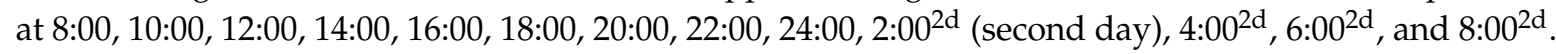
The light started from 8 o'clock and ended at 24 o'clock, followed by $8 \mathrm{~h}$ of darkness. For abiotic stresses treatment, the untreated apple seedlings were transferred to water-cultured conditions. Under normal photoperiod conditions, the seedlings with the same growth state were treated in $\mathrm{NaCl}(100 \mathrm{mM})$, polyethylene glycol 6000 (PEG 6000, 8\%), IAA $(100 \mu \mathrm{M})$, ABA $(100 \mu \mathrm{M})$, and gibberellin (GA) $(100 \mu \mathrm{M})$, respectively [65,66]. These seedlings were collected at $0 \mathrm{~h}, 1 \mathrm{~h}, 2 \mathrm{~h}, 3 \mathrm{~h}, 6 \mathrm{~h}$, and $12 \mathrm{~h}$ after treatment, immediately frozen by liquid nitrogen, and stored at $-80^{\circ} \mathrm{C}$ for further analysis [67].

The 'Orin' apple (Golden Delicious $\times$ Indo) calluses were cultured on MS medium containing $1.5 \mathrm{mg} / \mathrm{L} 2,4-$ dichlorophenoxyacetic acid $(2,4-\mathrm{D})$ and $0.4 \mathrm{mg} / \mathrm{L} 6-\mathrm{BA}$ at $24{ }^{\circ} \mathrm{C}$ for $20 \mathrm{~d}$ in the dark [52].

\subsection{Plasmid Construction and Acquisition of the Transgenic Plant Material}

The full-length cDNA of MdPIF4 was cloned into the pRI 101-AN vector (Takara, Dalian, China) to obtain the MdPIF4 overexpression construct. Then, the pRI 101-AN empty vector and recombinant construct were transformed into Agrobacterium tumefaciens strain LBA4404. These agrobacteria were grown in lysogeny broth (LB) medium supplemented with $50 \mathrm{mg} / \mathrm{mL}$ kanamycin and $50 \mathrm{mg} / \mathrm{mL}$ rifampicin [68].

Transgenic apple calluses were obtained by agrobacterium-mediated transformation [69]. Briefly, the 14-day-old apple calluses were co-cultured with agrobacterium strains carrying the empty vector or recombinant constructs in the dark for $20 \mathrm{~min}$. Then the transformed apple calluses were plated on selective medium supplemented with $250 \mathrm{mg} / \mathrm{L}$ carbenicillin and $30 \mathrm{mg} / \mathrm{L}$ kanamycin [70]. The successfully transgenic apple calluses grew in about four weeks.

\subsection{Identification, Chromosomal Location, and Functional Annotation of the MdPIF Genes}

To identify the MdPIF genes from the Malus domestica genome, we downloaded eight PIF peptide sequences from the Arabidopsis database [71]. Then, MdPIFs were searched in the apple genome database (Malus domestica v1.0) using the Arabidopsis protein sequences [72]. Eight candidate protein sequences 
were screened out, and we next used the SMART database [73] to check whether these candidates contained the conserved bHLH and APB domains.

The chromosomal location of these genes were found in the apple genome annotation file (Malus domestica.v1.0.consensus.gff) from the Genome Database for Rosaceae (GDR) [74]. The MdPIF genes were submitted to online MG2C software [75] for gene chromosome mapping. The molecular mass, theoretical isoelectric point (pI), and protein hydrophobicity of these MdPIFs were analyzed using the online tool ProtParam [76].

\subsection{Phylogenetic Analysis of the PIF Proteins}

AtPIF protein sequences were obtained from the Arabidopsis database [71,77]. The PIF protein sequences of rice were obtained from the rice annotation project [78]. Based on all PIF protein sequences from Arabidopsis, rice, and apple, a phylogenetic tree was constructed using MEGA5.1 software via the neighbor-joining method with the following settings: Bootstrap method, 1000 replicates, and the Poisson model $[79,80]$.

\subsection{Gene Structure (Intron/Exon), Multiple Sequence Alignment, and Conserved Motif Analysis}

The apple genome database file (Malus domestica.v1.0.consensus.gff) was downloaded from the GDR database. Structure information of the MdPIF genes was drawn using the gene feature visualization server GSDS 2.0 [81-83]. The sequence alignment was performed using DANMAN software with default parameters [42,84]. The conserved motif analysis was carried out using the MEME program [85], and TBtools was used to display the motif structure [86].

\subsection{Analysis of Cis-Acting Elements in the MdPIF Promoters}

A 1500-bp fragment at the upstream of the start codon of the MdPIF genes was considered the promoter region, and the promoter sequences were submitted to PlantCARE [87] to analyze the cis-acting elements [88,89].

\subsection{RNA Extraction and Quantitative Real-Time PCR (qRT-PCR) Analysis}

Total RNAs were extracted with the RNAplant Plus Reagent Kit (Tiangen, Beijing, China). Reverse transcription was performed using the PrimeScript ${ }^{\mathrm{TM}}$ RT Reagent Kit (Takara, Shiga, Japan). The qRT-PCR reaction system contained $10 \mu \mathrm{L}$ SYBR premix Ex Taq ${ }^{\mathrm{TM}}$ (Takara), $0.8 \mu \mathrm{L}(10 \mathrm{mM})$ of each primer, and $50 \mathrm{ng}$ of cDNA, in a total volume of $20 \mu \mathrm{L}$. The qRT-PCR reaction procedure was performed according to methods previously reported [90]. The PCR experimental sample had three repetitions and $18 \mathrm{~S}$ ribosomal RNA served as a control [91]. The $2^{-\Delta \Delta C T} 2^{-\Delta \Delta C T}$ method was used for data analysis. All primers used in this study are shown in Table S1.

\subsection{Subcellular Localization Analysis}

The coding sequences of MdPIF1, MdPIF3, MdPIF4, and MdPIF8 were cloned into a 35S::GFP vector for translational fusion with the green fluorescent protein (GFP), respectively. The recombinant expression vectors 35S::MdPIF-GFP were transformed into the Agrobacterium LBA4400 strain, respectively. Then, the agrobacterium-harboring 35S::MdPIF-GFP constructs were injected into Nicotiana benthamiana leaves [92] and cultured in the dark for 2 days. GFP signal in cells was observed using a high-resolution confocal microscope (LSCM Meta; Carl Zeiss, Zena, Germany) [93].

\subsection{Transcriptional Activity Assay}

The coding sequences of MdPIF1, MdPIF3, MdPIF4, and MdPIF8 were cloned into the pGBKT7 vector using the homologous recombination method. Restriction endonuclease sites were EcoRI and SalI (Table S1). Since MdMYB23 (GenBank accession number: MDP0000230141) has been proven to have transcriptional activity in our laboratory [94], it was able to be used as a positive control. The pGBKT7-MdPIF fusion 
vectors, employing the pGBKT7 vector (negative control), and pGBKT7-MdMYB23 (positive control), were transferred into the yeast strain AH109. Then they were cultured on the SD medium (SD/-Trp, $\mathrm{SD} /$-Trp/-His/-Ade/X- $\alpha$-gal) at $28{ }^{\circ} \mathrm{C}$ for $3-5$ days.

\subsection{Apple Callus Treatment and Physiological Measurements}

The 14-day old WT and transgenic apple calluses were cultured on MS medium containing $0 \mu \mathrm{M}$, $50 \mu \mathrm{M}$, and $100 \mu \mathrm{M}$ ABA. An electronic balance (one thousandth) was used to measure the weight of apple calluses to determine the callus growth. Malondialdehyde (MDA) content was measured using the thiobarbituric acid method reported previously [43].

\subsection{Statistical Analysis}

All data were obtained from three independent experiments with three biological duplicates in each experiment. DPS software was used for significant difference analysis, and a $p$-value $<0.05$ was considered a significant difference [95]. Error bars represent the standard deviation.

\section{Conclusions}

We screened out seven MdPIF genes from the apple genome and four of them were selected as representative members for further investigation. We systematically analyzed the bioinformatic features of the MdPIFs and found that their expression could be affected by multiple abiotic stresses and hormones. Subcellular localization and transcriptional activity analysis showed that MdPIFs were typical nuclear transcription factors with transcriptional activation ability. Through analysis of transgenic apple calluses, we found overexpressed MdPIF4 in apple calluses reduces their sensitivity to ABA. Our data improved our understanding of the MdPIFs' functions, and also sheds light for future exploration of PIFs' critical roles in multiple biological processes in apples and other plant species.

Supplementary Materials: Supplementary materials can be found at http://www.mdpi.com/1422-0067/21/19/ 7350/s1.

Author Contributions: Y.-J.H., Z.-L.Z., and P.-F.Z. designed the research. P.-F.Z., X.W., and Y.-Y.Y. performed the experiments. P.-F.Z., C.-X.Y., and Z.-L.Z. analyzed the data. P.-F.Z., Z.-L.Z., and Y.-J.H. wrote and revised the manuscript. All authors have read and agreed to the published version of the manuscript.

Funding: This work was supported by a grant from the National Natural Science Foundation of China (31901988), NSFC (31772288), the National Key Research and Development Program of China (2018YFD1000100), the Science and Technology Program of Yunnan Province (2019ZG002-1-03), the Major Program of Shandong Provincial Natural Science Foundation (ZR2018MC021), and the Ministry of Agriculture of China (CARS-27).

Conflicts of Interest: The authors declare no conflict of interest.

\section{Abbreviations}

bHLH Basic helix-loop-helix

APB Active phyB-binding

APA Active phyA-binding

ABA Abscisic acid

\section{References}

1. Chen, M.; Chory, J.; Fankhauser, C. Light signal transduction in higher plants. Annu. Rev. Genet. 2004, 38, 87-117. [CrossRef] [PubMed]

2. Sullivan, J.A.; Deng, X.W. From seed to seed: The role of photoreceptors in Arabidopsis development. Dev. Biol. 2003, 260, 289-297. [CrossRef]

3. Franklin, K.A.; Larner, V.S.; Whitelam, G.C. The signal transducing photoreceptors of plants. Int. J. Dev. Biol. 2005, 49, 653-664. [CrossRef] [PubMed] 
4. Franklin, K.A.; Praekelt, U.; Stoddart, W.M.; Billingham, O.E.; Halliday, K.J.; Whitelam, G.C. Phytochromes B, D, and E act redundantly to control multiple physiological responses in Arabidopsis. Plant Physiol. 2003, 131, 1340-1346. [CrossRef]

5. Li, J.; Li, G.; Wang, H.; Wang Deng, X. Phytochrome signaling mechanisms. Arab. Book 2011, 9, e0148. [CrossRef]

6. Van Buskirk, E.K.; Decker, P.V.; Chen, M. Photobodies in light signaling. Plant Physiol. 2012, 158, 52-60. [CrossRef]

7. Klose, C.; Viczian, A.; Kircher, S.; Schafer, E.; Nagy, F. Molecular mechanisms for mediating light-dependent nucleo/cytoplasmic partitioning of phytochrome photoreceptors. New Phytol. 2015, 206, 965-971. [CrossRef]

8. Leivar, P.; Quail, P.H. PIFs: Pivotal components in a cellular signaling hub. Trends Plant Sci. 2011, 16, 19-28. [CrossRef]

9. Pham, V.N.; Kathare, P.K.; Huq, E. Phytochromes and Phytochrome Interacting Factors. Plant Physiol. 2018, 176, 1025-1038. [CrossRef] [PubMed]

10. Zhang, X.; Huai, J.; Shang, F.; Xu, G.; Tang, W.; Jing, Y.; Lin, R. A PIF1/PIF3-HY5-BBX23 Transcription Factor Cascade Affects Photomorphogenesis. Plant Physiol. 2017, 174, 2487-2500. [CrossRef] [PubMed]

11. Luo, Q.; Lian, H.L.; He, S.B.; Li, L.; Jia, K.P.; Yang, H.Q. COP1 and phyB Physically Interact with PIL1 to Regulate Its Stability and Photomorphogenic Development in Arabidopsis. Plant Cell 2014, 26, 2441-2456. [CrossRef] [PubMed]

12. Leivar, P.; Monte, E. PIFs: Systems integrators in plant development. Plant Cell 2014, 26, 56-78. [CrossRef] [PubMed]

13. Ni, M.; Tepperman, J.M.; Quail, P.H. PIF3, a phytochrome-interacting factor necessary for normal photoinduced signal transduction, is a novel basic helix-loop-helix protein. Cell 1998, 95, 657-667. [CrossRef]

14. Khanna, R.; Huq, E.; Kikis, E.A.; Al-Sady, B.; Lanzatella, C.; Quail, P.H. A novel molecular recognition motif necessary for targeting photoactivated phytochrome signaling to specific basic helix-loop-helix transcription factors. Plant Cell 2004, 16, 3033-3044. [CrossRef]

15. Shen, H.; Zhu, L.; Castillon, A.; Majee, M.; Downie, B.; Huq, E. Light-induced phosphorylation and degradation of the negative regulator PHYTOCHROME-INTERACTING FACTOR1 from Arabidopsis depend upon its direct physical interactions with photoactivated phytochromes. Plant Cell 2008, 20, 1586-1602. [CrossRef]

16. Huq, E.; Quail, P.H. PIF4, a phytochrome-interacting bHLH factor, functions as a negative regulator of phytochrome B signaling in Arabidopsis. EMBO J. 2002, 21, 2441-2450. [CrossRef]

17. Oh, E.; Kim, J.; Park, E.; Kim, J.I.; Kang, C.; Choi, G. PIL5, a phytochrome-interacting basic helix-loop-helix protein, is a key negative regulator of seed germination in Arabidopsis thaliana. Plant Cell 2004, 16, 3045-3058. [CrossRef]

18. Shin, J.; Park, E.; Choi, G. PIF3 regulates anthocyanin biosynthesis in an HY5-dependent manner with both factors directly binding anthocyanin biosynthetic gene promoters in Arabidopsis. Plant J. 2007, 49, 981-994. [CrossRef]

19. Paik, I.; Kathare, P.K.; Kim, J.I.; Huq, E. Expanding Roles of PIFs in Signal Integration from Multiple Processes. Mol. Plant 2017, 10, 1035-1046. [CrossRef]

20. Quint, M.; Delker, C.; Franklin, K.A.; Wigge, P.A.; Halliday, K.J.; van Zanten, M. Molecular and genetic control of plant thermomorphogenesis. Nat. Plants 2016, 2, 1-9. [CrossRef]

21. Casal, J.J.; Balasubramanian, S. Thermomorphogenesis. Annu. Rev. Plant Biol. 2019, 70, 321-346. [CrossRef] [PubMed]

22. Gao, Y.; Wu, M.; Zhang, M.; Jiang, W.; Ren, X.; Liang, E.; Zhang, D.; Zhang, C.; Xiao, N.; Li, Y.; et al. A maize phytochrome-interacting factors protein ZmPIF1 enhances drought tolerance by inducing stomatal closure and improves grain yield in Oryza sativa. Plant Biotechnol. J. 2018, 16, 1375-1387. [CrossRef] [PubMed]

23. Gao, Y.; Jiang, W.; Dai, Y.; Xiao, N.; Zhang, C.; Li, H.; Lu, Y.; Wu, M.; Tao, X.; Deng, D.; et al. A maize phytochromeinteracting factor 3 improves drought and salt stress tolerance in rice. Plant Mol. Biol. 2015, 87, 413-428. [CrossRef] [PubMed]

24. Kim, D.H.; Yamaguchi, S.; Lim, S.; Oh, E.; Park, J.; Hanada, A.; Kamiya, Y.; Choi, G. SOMNUS, a CCCH-type zinc finger protein in Arabidopsis, negatively regulates light-dependent seed germination downstream of PIL5. Plant Cell 2008, 20, 1260-1277. [CrossRef] [PubMed] 
25. Kim, J.; Kang, H.; Park, J.; Kim, W.; Yoo, J.; Lee, N.; Kim, J.; Yoon, T.Y.; Choi, G. PIF1-Interacting Transcription Factors and Their Binding Sequence Elements Determine the in vivo Targeting Sites of PIF1. Plant Cell 2016, 28, 1388-1405. [CrossRef]

26. Koini, M.A.; Alvey, L.; Allen, T.; Tilley, C.A.; Harberd, N.P.; Whitelam, G.C.; Franklin, K.A. High temperature-mediated adaptations in plant architecture require the bHLH transcription factor PIF4. Curr. Biol. 2009, 19, 408-413. [CrossRef]

27. Kumar, S.V.; Lucyshyn, D.; Jaeger, K.E.; Alos, E.; Alvey, E.; Harberd, N.P.; Wigge, P.A. Transcription factor PIF4 controls the thermosensory activation of flowering. Nature 2012, 484, 242-245. [CrossRef]

28. Lau, O.S.; Deng, X.W. Plant hormone signaling lightens up: Integrators of light and hormones. Curr. Opin. Plant Biol. 2010, 13, 571-577. [CrossRef]

29. Xu, J.N.; Xing, S.S.; Zhang, Z.R.; Chen, X.S.; Wang, X.Y. Genome-Wide Identification and Expression Analysis of the Tubby-Like Protein Family in the Malus domestica Genome. Front. Plant Sci. 2016, 7, 1693. [CrossRef]

30. An, J.P.; Li, R.; Qu, F.J.; You, C.X.; Wang, X.F.; Hao, Y.J. Apple F-Box Protein MdMAX2 Regulates Plant Photomorphogenesis and Stress Response. Front. Plant Sci. 2016, 7, 1685. [CrossRef]

31. Zhou, L.J.; Mao, K.; Qiao, Y.; Jiang, H.; Li, Y.Y.; Hao, Y.J. Functional identification of MdPIF1 as a Phytochrome Interacting Factor in Apple. Plant Physiol. Biochem. 2017, 119, 178-188. [CrossRef] [PubMed]

32. Mao, K.; Dong, Q.; Li, C.; Liu, C.; Ma, F. Genome Wide Identification and Characterization of Apple bHLH Transcription Factors and Expression Analysis in Response to Drought and Salt Stress. Front. Plant Sci. 2017, 8, 480. [CrossRef] [PubMed]

33. Nusinow, D.A.; Helfer, A.; Hamilton, E.E.; King, J.J.; Imaizumi, T.; Schultz, T.F.; Farre, E.M.; Kay, S.A. The ELF4-ELF3-LUX complex links the circadian clock to diurnal control of hypocotyl growth. Nature 2011, 475, 398-402. [CrossRef] [PubMed]

34. Toledo-Ortiz, G.; Johansson, H.; Lee, K.P.; Bou-Torrent, J.; Stewart, K.; Steel, G.; Rodriguez-Concepcion, M.; Halliday, K.J. The HY5-PIF regulatory module coordinates light and temperature control of photosynthetic gene transcription. PLoS Genet. 2014, 10, e1004416. [CrossRef]

35. Giuliano, G.; Pichersky, E.; Malik, V.S.; Timko, M.P.; Scolnik, P.A.; Cashmore, A.R. An evolutionarily conserved protein binding sequence upstream of a plant light-regulated gene. Proc. Natl. Acad. Sci. USA 1988, 85, 7089-7093. [CrossRef]

36. Shi, Q.; Zhang, H.; Song, X.; Jiang, Y.; Liang, R.; Li, G. Functional Characterization of the Maize PhytochromeInteracting Factors PIF4 and PIF5. Front. Plant Sci. 2017, 8, 2273. [CrossRef]

37. Nozue, K.; Covington, M.F.; Duek, P.D.; Lorrain, S.; Fankhauser, C.; Harmer, S.L.; Maloof, J.N. Rhythmic growth explained by coincidence between internal and external cues. Nature 2007, 448, 358-361. [CrossRef]

38. Wu, G.; Zhao, Y.; Shen, R.; Wang, B.; Xie, Y.; Ma, X.; Zheng, Z.; Wang, H. Characterization of Maize Phytochrome-Interacting Factors in Light Signaling and Photomorphogenesis. Plant Physiol. 2019, 181, 789-803. [CrossRef]

39. Dey, S.; Kundu, R.; Gopal, G.; Mukherjee, A.; Nag, A.; Paul, S. Enhancement of nitrogen assimilation and photosynthetic efficiency by novel iron pulsing technique in Oryza sativa L. var Pankaj. Plant Physiol. Biochem. 2019, 144, 207-221. [CrossRef]

40. Yamane, K.; Mitsuya, S.; Kawasaki, M.; Taniguchi, M.; Miyake, H. Antioxidant capacity and damages caused by salinity stress in apical and basal regions of rice leaf. Plant Prod. Sci. 2009, 12, 319-326. [CrossRef]

41. Malenčić, D.; Vasić, D.; Popović, M.; Dević, D. Antioxidant systems in sunflower as affected by oxalic acid. Biol. Plant. 2004, 48, 243-247. [CrossRef]

42. Zhang, C.L.; Mao, K.; Zhou, L.J.; Wang, G.L.; Zhang, Y.L.; Li, Y.Y.; Hao, Y.J. Genome-wide identification and characterization of apple long-chain Acyl-CoA synthetases and expression analysis under different stresses. Plant Physiol. Biochem. 2018, 132, 320-332. [CrossRef]

43. Ma, Q.J.; Sun, M.H.; Lu, J.; Liu, Y.J.; You, C.X.; Hao, Y.J. An apple CIPK protein kinase targets a novel residue of AREB transcription factor for ABA-dependent phosphorylation. Plant Cell Environ. 2017, 40, 2207-2219. [CrossRef] [PubMed]

44. Velasco, R.; Zharkikh, A.; Affourtit, J.; Dhingra, A.; Cestaro, A.; Kalyanaraman, A.; Fontana, P.; Bhatnagar, S.K.; Troggio, M.; Pruss, D.; et al. The genome of the domesticated apple (Malus x domestica Borkh.). Nat. Genet. 2010, 42, 833-839. [CrossRef] [PubMed] 
45. Li, X.; Kui, L.; Zhang, J.; Xie, Y.; Wang, L.; Yan, Y.; Wang, N.; Xu, J.; Li, C.; Wang, W.; et al. Improved hybrid de novo genome assembly of domesticated apple (Malus $\mathrm{x}$ domestica). Gigascience 2016, 5, 35. [CrossRef] [PubMed]

46. Daccord, N.; Celton, J.M.; Linsmith, G.; Becker, C.; Choisne, N.; Schijlen, E.; van de Geest, H.; Bianco, L.; Micheletti, D.; Velasco, R.; et al. High-quality de novo assembly of the apple genome and methylome dynamics of early fruit development. Nat. Genet. 2017, 49, 1099-1106. [CrossRef]

47. Cao, Z.H.; Zhang, S.Z.; Wang, R.K.; Zhang, R.F.; Hao, Y.J. Genome wide analysis of the apple MYB transcription factor family allows the identification of MdoMYB121 gene confering abiotic stress tolerance in plants. PLoS ONE 2013, 8, e69955. [CrossRef]

48. Meng, D.; Li, Y.; Bai, Y.; Li, M.; Cheng, L. Genome-wide identification and characterization of WRKY transcriptional factor family in apple and analysis of their responses to waterlogging and drought stress. Plant Physiol. Biochem. 2016, 103, 71-83. [CrossRef]

49. Liu, X.; Li, R.; Dai, Y.; Chen, X.; Wang, X. Genome-wide identification and expression analysis of the B-box gene family in the Apple (Malus domestica Borkh.) genome. Mol. Genet. Genom. 2018, 293, 303-315. [CrossRef]

50. Hu, D.G.; Sun, C.H.; Ma, Q.J.; You, C.X.; Cheng, L.; Hao, Y.J. MdMYB1 Regulates Anthocyanin and Malate Accumulation by Directly Facilitating Their Transport into Vacuoles in Apples. Plant Physiol. 2016, 170, 1315-1330. [CrossRef]

51. An, J.P.; Zhang, X.W.; You, C.X.; Bi, S.Q.; Wang, X.F.; Hao, Y.J. MdWRKY40 promotes wounding-induced anthocyanin biosynthesis in association with MdMYB1 and undergoes MdBT2-mediated degradation. New Phytol. 2019, 224, 380-395. [CrossRef] [PubMed]

52. An, J.P.; Wang, X.F.; Zhang, X.W.; Bi, S.Q.; You, C.X.; Hao, Y.J. MdBBX22 regulates UV-B-induced anthocyanin biosynthesis through regulating the function of MdHY5 and is targeted by MdBT2 for $26 \mathrm{~S}$ proteasome-mediated degradation. Plant Biotechnol. J. 2019, 17, 2231-2233. [CrossRef] [PubMed]

53. Nakamura, Y.; Kato, T.; Yamashino, T.; Murakami, M.; Mizuno, T. Characterization of a set of phytochromeinteracting factor-like bHLH proteins in Oryza sativa. Biosci. Biotechnol. Biochem. 2007, 71, 1183-1191. [CrossRef] [PubMed]

54. Jeong, J.; Choi, G. Phytochrome-interacting factors have both shared and distinct biological roles. Mol. Cells 2013, 35, 371-380. [CrossRef] [PubMed]

55. Wang, F.; Chen, X.; Dong, S.; Jiang, X.; Wang, L.; Yu, J.; Zhou, Y. Crosstalk of PIF4 and DELLA modulates CBF transcript and hormone homeostasis in cold response in tomato. Plant Biotechnol. J. 2020, 18, 1041-1055. [CrossRef]

56. Choi, H.; Oh, E. PIF4 Integrates Multiple Environmental and Hormonal Signals for Plant Growth Regulation in Arabidopsis. Mol. Cells 2016, 39, 587-593. [CrossRef]

57. Gangappa, S.N.; Berriri, S.; Kumar, S.V. PIF4 Coordinates Thermosensory Growth and Immunity in Arabidopsis. Curr. Biol. 2017, 27, 243-249. [CrossRef]

58. Box, M.S.; Huang, B.E.; Domijan, M.; Jaeger, K.E.; Khattak, A.K.; Yoo, S.J.; Sedivy, E.L.; Jones, D.M.; Hearn, T.J.; Webb, A.A.R.; et al. ELF3 controls thermoresponsive growth in Arabidopsis. Curr. Biol. 2015, 25, 194-199. [CrossRef]

59. Verma, V.; Ravindran, P.; Kumar, P.P. Plant hormone-mediated regulation of stress responses. BMC Plant Biol. 2016, 16, 86. [CrossRef]

60. Zhou, S.S.; Ma, S.X.; Li, M.J.; Li, C.Y.; Gong, X.Q.; Guan, Q.M.; Tan, Y.X.; Shao, Y.; Li, C.; Ma, F.W. Comprehensive genomic analysis and expression profiling of Argonaute gene family and examination of their regulatory roles in water-use efficiency and abiotic stress responses in apple. Acta Physiol. Plant 2016, 38, 231. [CrossRef]

61. Li, H.L.; Wang, X.; Ji, X.L.; Qiao, Z.W.; You, C.X.; Hao, Y.J. Genome-Wide Identification of Apple Ubiquitin SINA E3 Ligase and Functional Characterization of MdSINA2. Front. Plant Sci. 2020, 11, 1109. [CrossRef] [PubMed]

62. Zhong, M.S.; Jiang, H.; Cao, Y.; Wang, Y.X.; You, C.X.; Li, Y.Y.; Hao, Y.J. MdCER2 conferred to wax accumulation and increased drought tolerance in plants. Plant Physiol. Biochem. 2020, 149, 277-285. [CrossRef] [PubMed]

63. Dong, Q.; Duan, D.; Zhao, S.; Xu, B.; Luo, J.; Wang, Q.; Huang, D.; Liu, C.; Li, C.; Gong, X.; et al. Genome-Wide Analysis and Cloning of the Apple Stress-Associated Protein Gene Family Reveals MdSAP15, Which Confers Tolerance to Drought and Osmotic Stresses in Transgenic Arabidopsis. Int. J. Mol. Sci. 2018, 19, 2478. [CrossRef] [PubMed] 
64. Ren, Y.R.; Yang, Y.Y.; Zhang, R.; You, C.X.; Zhao, Q.; Hao, Y.J. MdGRF11, an apple 14-3-3 protein, acts as a positive regulator of drought and salt tolerance. Plant Sci. 2019, 288, 110219. [CrossRef] [PubMed]

65. Yang, Y.Y.; Ren, Y.R.; Zheng, P.F.; Zhao, L.L.; You, C.X.; Wang, X.F.; Hao, Y.J. Cloning and functional identification of a strigolactone receptor gene MdD14 in apple. Plant Cell Tissue Organ Cult. 2019. [CrossRef]

66. Lian, X.Y.; Wang, X.; Gao, H.N.; Jiang, H.; Mao, K.; You, C.X.; Li, Y.Y.; Hao, Y.J. Genome wide analysis and functional identification of MdKCS genes in apple. Plant Physiol. Biochem. 2020, 151, 299-312. [CrossRef]

67. Zhang, Y.L.; Zhang, C.L.; Wang, G.L.; Wang, Y.X.; Qi, C.H.; You, C.X.; Li, Y.Y.; Hao, Y.J. Apple AP2/EREBP transcription factor MdSHINE2 confers drought resistance by regulating wax biosynthesis. Planta 2019, 249, 1627-1643. [CrossRef]

68. An, J.P.; Li, H.H.; Song, L.Q.; Su, L.; Liu, X.; You, C.X.; Wang, X.F.; Hao, Y.J. The molecular cloning and functional characterization of MdMYC2, a bHLH transcription factor in apple. Plant Physiol. Biochem. 2016, 108, 24-31. [CrossRef]

69. An, J.P.; Yao, J.F.; Xu, R.R.; You, C.X.; Wang, X.F.; Hao, Y.J. Apple bZIP transcription factor MdbZIP44 regulates abscisic acid-promoted anthocyanin accumulation. Plant Cell Environ. 2018, 41, 2678-2692. [CrossRef]

70. Zhao, Q.; Ren, Y.R.; Wang, Q.J.; Wang, X.F.; You, C.X.; Hao, Y.J. Ubiquitination-Related MdBT Scaffold Proteins Target a bHLH Transcription Factor for Iron Homeostasis. Plant Physiol. 2016, 172, 1973-1988. [CrossRef]

71. Arabidopsis Database. Available online: https://www.arabidopsis.org/index.jsp (accessed on 30 July 2020).

72. Apple Genome Database. Available online: https://phytozome.jgi.doe.gov/pz/portal.html (accessed on 30 July 2020).

73. SMART Database. Available online: http://smart.embl-heidelberg.de (accessed on 30 July 2020).

74. GDR Database. Available online: http://www.rosaceae.org (accessed on 30 July 2020).

75. MG2C Software. Available online: http://mg2c.iask.in/mg2c_v2.0 (accessed on 30 July 2020).

76. ProtParam Tool. Available online: http://web.expasy.org/protparam (accessed on 30 July 2020).

77. Wang, Q.; Liu, C.; Dong, Q.; Huang, D.; Li, C.; Li, P.; Ma, F. Genome-Wide Identification and Analysis of Apple NITRATE TRANSPORTER 1/PEPTIDE TRANSPORTER Family (NPF) Genes Reveals MdNPF6.5 Confers High Capacity for Nitrogen Uptake under Low-Nitrogen Conditions. Int. J. Mol. Sci. 2018, 19, 2761. [CrossRef] [PubMed]

78. Rice Database. Available online: https://rapdb.dna.affrc.go.jp (accessed on 30 July 2020).

79. Sun, Q.; Jiang, S.; Zhang, T.; Xu, H.; Fang, H.; Zhang, J.; Su, M.; Wang, Y.; Zhang, Z.; Wang, N.; et al. Apple NAC transcription factor MdNAC52 regulates biosynthesis of anthocyanin and proanthocyanidin through MdMYB9 and MdMYB11. Plant Sci. 2019, 289, 110286. [CrossRef] [PubMed]

80. Tamura, K.; Peterson, D.; Peterson, N.; Stecher, G.; Nei, M.; Kumar, S. MEGA5: Molecular evolutionary genetics analysis using maximum likelihood, evolutionary distance, and maximum parsimony methods. Mol. Biol. Evol. 2011, 28, 2731-2739. [CrossRef] [PubMed]

81. GSDS 2.0 software. Available online: http://gsds.cbi.pku.edu.cn (accessed on 30 July 2020).

82. Hu, B.; Jin, J.; Guo, A.Y.; Zhang, H.; Luo, J.; Gao, G. GSDS 2.0: An upgraded gene feature visualization server. Bioinformatics 2015, 31, 1296-1297. [CrossRef] [PubMed]

83. Shen, L.B.; Yao, Y.; He, H.; Qin, Y.L.; Liu, Z.J.; Liu, W.X.; Qi, Z.Q.; Yang, L.J.; Cao, Z.M.; Yang, Y. Genome-Wide Identification, Expression, and Functional Analysis of the Alkaline/Neutral Invertase Gene Family in Pepper. Int. J. Mol. Sci. 2018, 19, 224. [CrossRef] [PubMed]

84. DNAMAN Software. Available online: http://dnaman.software.informer.com/ (accessed on 30 July 2020).

85. MEME Program. Available online: http://meme.nbcr.net/meme/intro.html (accessed on 30 July 2020).

86. Ma, B.; Yuan, Y.; Gao, M.; Qi, T.; Li, M.; Ma, F. Genome-Wide Identification, Molecular Evolution, and Expression Divergence of Aluminum-Activated Malate Transporters in Apples. Int. J. Mol. Sci. 2018, 19, 2807. [CrossRef] [PubMed]

87. PlantCARE Tool. Available online: http://bioinformatics.psb.ugent.be/webtools/plantcare/html/ (accessed on 30 July 2020).

88. Lescot, M.; Dehais, P.; Thijs, G.; Marchal, K.; Moreau, Y.; Van de Peer, Y.; Rouze, P.; Rombauts, S. PlantCARE, a database of plant cis-acting regulatory elements and a portal to tools for in silico analysis of promoter sequences. Nucleic Acids Res. 2002, 30, 325-327. [CrossRef]

89. Qi, C.H.; Zhao, X.Y.; Jiang, H.; Zheng, P.F.; Liu, H.T.; Li, Y.Y.; Hao, Y.J. Isolation and functional identification of an apple MdCER1 gene. Plant Cell Tissue Organ Cult. 2019, 136, 1-13. [CrossRef] 
90. An, J.P.; Zhang, X.W.; Xu, R.R.; You, C.X.; Wang, X.F.; Hao, Y.J. Apple MdERF4 negatively regulates salt tolerance by inhibiting MdERF3 transcription. Plant Sci. 2018, 276, 181-188. [CrossRef]

91. Ma, Q.J.; Sun, M.H.; Lu, J.; Liu, Y.J.; Hu, D.G.; Hao, Y.J. Transcription Factor AREB2 Is Involved in Soluble Sugar Accumulation by Activating Sugar Transporter and Amylase Genes. Plant Physiol. 2017, 174, 2348-2362. [CrossRef]

92. Sun, M.H.; Ma, Q.J.; Hu, D.G.; Zhu, X.P.; You, C.X.; Shu, H.R.; Hao, Y.J. The Glucose Sensor MdHXK1 Phosphorylates a Tonoplast $\mathrm{Na}(+) / \mathrm{H}(+)$ Exchanger to Improve Salt Tolerance. Plant Physiol. 2018, 176, 2977-2990. [CrossRef] [PubMed]

93. Zhao, X.Y.; Qi, C.H.; Jiang, H.; Zheng, P.F.; Zhong, M.S.; Zhao, Q.; You, C.X.; Li, Y.Y.; Hao, Y.J. Functional identification of apple on MdHIR4 in biotic stress. Plant Sci. 2019, 283, 396-406. [CrossRef] [PubMed]

94. An, J.P.; Li, R.; Qu, F.J.; You, C.X.; Wang, X.F.; Hao, Y.J. R2R3-MYB transcription factor MdMYB23 is involved in the cold tolerance and proanthocyanidin accumulation in apple. Plant J. 2018, 96, 562-577. [CrossRef] [PubMed]

95. Hu, D.G.; Yu, J.Q.; Han, P.L.; Xie, X.B.; Sun, C.H.; Zhang, Q.Y.; Wang, J.H.; Hao, Y.J. The regulatory module MdPUB29-MdbHLH3 connects ethylene biosynthesis with fruit quality in apple. New Phytol. 2019, 221, 1966-1982. [CrossRef] [PubMed]

(C) 2020 by the authors. Licensee MDPI, Basel, Switzerland. This article is an open access article distributed under the terms and conditions of the Creative Commons Attribution (CC BY) license (http://creativecommons.org/licenses/by/4.0/). 